\title{
Efisiensi Daya Perangkat Wireless Sensor Network Pada Penerangan Jalan Umum (PJU) Berbasis Algoritma Leach
}

\author{
Aad Hariyadi ${ }^{1}$, Mochamad Taufik ${ }^{2}$, Hudiono ${ }^{3}$, Nurul Hidayati ${ }^{4}$, Amalia Eka \\ Rakhmania $^{5}$, Ridho Hendra Yoga Perdana ${ }^{6}$ \\ 1,2,3,4,5,6Jurusan Teknik Elektro, \\ Politeknik Negeri Malang, Malang \\ 1aad.hariyadi@polinema.ac.id, ${ }^{2}$ moch.taufik@polinema.ac.id, ${ }^{3 h}$ udiono@polinema.ac.id, \\ ${ }^{4}$ nurulhid8@polinema.ac.id, 5amaliaeka.rakhmania@polinema.ac.id, \\ ${ }^{6}$ ridho.hendra@polinema.ac.id.
}

\begin{abstract}
Abstrak
Penggunaan energi saat ini sedang menjadi sorotan pemerintah Indonesia. Salah satu kendalanya adalah penggunaan Penerangan Jalan Umum (PJU). Dengan membuat setiap penerangan jalan umum dapat berkomunikasi, pemerintah dapat memantau setiap penggunaan daya pada penerangan dengan menggunakan algoritma Leach, yang berfokus pada efisiensi daya dalam jaringan untuk menghemat penggunaan daya. Dalam algoritma Leach yang diusulkan, node akan mengirim data ke server melalui kepala cluster yang dipilih. Kemudian kepala cluster akan meneruskan data tersebut ke node master yang secara otomatis terhubung ke server. Dengan mengambil pendekatan seperti itu, penggunaan daya di setiap node akan efisien. Performa yang diperoleh dapat mencapai efisiensi $42 \%$ pada proses pengujian dibandingkan tanpa menggunakan algoritma Leach.
\end{abstract}

Kata kunci: wireless sensor network, algoritma Leach, efisiensi, energi, jaringan

\begin{abstract}
The use of energy is currently in the spotlight of the Indonesian government. One of the problems is the use of public street lighting. By making every public street lighting able to communicate, the government can monitor every power usage in the lighting by using the Leach algorithm, which focuses on power efficiency in the network to save power usage. In the proposed Leach algorithm, the node will send data to the server via a selected cluster head. Then the cluster head will forward the data to the master node automatically connected to the server. By taking such an approach, the power usage at each node will be efficient. The performance obtained can reach an efficiency of $42 \%$ in the testing process compared to without using the Leach algorithm.
\end{abstract}

Keywords: wireless sensor network, Leach algorithm, efficiency, energy, network

\section{Pendahuluan}

Instansi pemerintah sedang gencar mencanangkan penghematan energi pada Penerangan jalan umum [1]. Pengadaan layanan lampu penerangan di area publik menjadi perhatian penting karena membutuhkan $10-20 \%$ energi listrik dari total konsumsi daya listrik suatu negara [2]-[3]. Untuk menangani permasalahan pemborosan energi pemerintah berupaya melakukan penghematan energi pada penerangan jalan umum (PJU) 
yaitu dengan pengendalian dan pemantauan jarak jauh pada PJU tersebut [4]-[5]. Saat ini terdapat teknologi wireless yang dengan penggunaan daya rendah serta efisien ketika digunakan untuk pemantauan dan pengendalian yang disebut Wireless Sensor Network (WSN)[4]-[6]. WSN merupakan suatu jaringan yang terdiri dari beberapa sensor node yang bersifat individu dan diletakkan ditempat-tempat yang ditentukan [7]. Sistem ini bertujuan untuk memantau kondisi suatu area dan dapat berinteraksi dengan lingkungannya dengan cara sensing, controlling dan communication terhadap parameterparameter yang digunakan [7]. Namun tiap sensor node ini mempunyai keterbatasan dalam beberapa hal, salah satu masalah pada penerapan jaringan WSN adalah daya dan lifetime setiap perangkat node yang digunakan dalam jaringan [8]-[9]. Pemecahan masalah yang banyak dilakukan adalah dengan pengembangan dalam sistem komunikasi pada WSN [8]. Salah satu algoritma yang dikembangkan untuk efisiensi energi adalah algoritma low energy adaptive clustering hierarchy (Leach)[10]-[11]. Algoritma ini memiliki cara kerja sistem yang melakukan rotasi terhadap cluster head $(\mathrm{CH})$ sebagai leader dari masing-masing node, yang pemilihannya dilakukan secara acak. Karena sifatnya yang acak, distribusi $\mathrm{CH}$ menjadi tidak seragam [11]. Namun dengan cara seperti itu sistem ini mampu membangun cluster pada node yang saling berdekatan [12].

Pada penelitian ini diusulkan implementasi algoritma Leach pada WSN yang diterapkan pada PJU untuk pemantauan jarak jauh. Sistem ini diimplementasikan dengan tujuan menghemat daya pada setiap node WSN yang digunakan serta mengefisiensikan energi yang digunakan pada perangkat komunikasi. Pada pendekatan ini, node akan mengirimkan data ke master node (MS) melalui $\mathrm{CH}$. Sehingga pengiriman data ke MS hanya dilakukan oleh $\mathrm{CH}$, kemudian diteruskan ke server. Sehingga energi yang dikonsumsi masing-masing node sensor menjadi lebih rendah. Hasil dari penelitian ini diharapkan dapat mengurangi penggunaan daya untuk setiap node dan meningkatkan efisiensi energi yang digunakan pada perangkat WSN. Selain itu, penghematan energi akan diatur sedemikian rupa untuk tidak mengurangi kualitas informasi data yang dikirimkan.

\section{Tinjauan Pustaka}

\subsection{Wireless Sensor Network}

Wireless Sensor Network (WSN) adalah kumpulan sejumlah node yang berkomunikasi secara wireless dalam sebuah jaringan yang sama dan dapat bekerjasama [12]. Pada setiap node yang terdapat pada WSN terdiri atas tiga komponen utama, yakni radio transceiver sebagai alat komunikasi wireless, mikrokontroler, dan sumber energi. Implementasi pemantauan dan pengendalian jarak jauh banyak yang menggunakan WSN [13].

WSN secara keseluruhan harus mampu dan handal dalam membaca kondisi objek yang sedang dipantau. Selain itu node sensor yang digunakan harus memiliki kepekaan atau sensitivitas yang tinggi. Dalam sebuah node, selain bekerja antar komponen, node sensor juga harus berkomunikasi dengan master node menggunakan komunikasi wireless. Sedangkan pada master node bertugas melakukan analisa, pemantauan dan penyimpanan data hasil deteksi dari sensor[13].

Proses node mulai dari sensing hingga pengiriman data menuju server dengan kapasitas yang berbeda, menjadi penyebab penggunaan daya yang tinggi, sedangkan sensor node biasanya terletak pada pada lokasi yang sumber listriknya terbatas. Maka sistem yang digunakan harus rendah konsumsi energi tetapi tidak mempengaruhi proses pengiriman data [13]. 
Kehandalan suatu WSN dapat ditunjukkan dengan beberapa karakteristik sebagai berikut [13]:

a. Ukuran yang kecil, node sensor harus memiliki ukuran yang fleksibel untuk dapat diletakkan pada berbagai lokasi.

b. Low limited power, karena penempatan node yang tidak bisa terus menerus mengisi ulang daya, maka cara kerja sebuah node harus seoptimal mungkin agar mempunyai konsumsi daya rendah.

c. Low cost, perancangan pada node sebisa mungkin menggunakan komponenkomponen yang mudah didapat dengan biaya rendah.

d. Self-organizing, node sensor harus mampu melakukan komunikasi dan mengkonfigurasi konektivitas pada topologi yang berubah-ubah sesuai dengan sistem secara mandiri.

e. Tipe layanan, data yang dikirimkan oleh node merupakan data hasil deteksi sensor, penggunaan sensor bergantung pada objek yang ingin dilihat nilainya.

f. Keandalan, suatu node diatur untuk mampu mengontrol dan memantau data pada objek yang dideteksi serta melakukan perbaikan ketika terdapat kesalahan dalam komunikasi data.

g. Lifetime, masa hidup sebuah node harus dalam jangka panjang, maka pertimbangan pemilihan komponen dan algoritma sangat diperlukan.

Namun, dalam penggunaan energi satu suatu jaringan memiliki keterbatasan dan harus diperbaiki, karena tidak sedikit WSN yang digunakan pada lingkungan yang minim energi. Terdapat beberapa faktor yang dapat menjadi kendala pada implementasi node, di antaranya [13]:

a. Jarak antar node atau dengan master node. Pemborosan energi pada node disebabkan oleh peletakkan jarak yang sangat jauh, sehingga permasalahan ini harus diatasi menggunakan algoritma routing yang berbasis hemat energi.

b. Ukuran data. Ketersediaan kanal bandwidth pada pengiriman data WSN dipengaruhi oleh besar kecil data yang dikirim. Maka diperlukan sistem pemampatan data tanpa merusak data yang dikirim.

c. Idle listening. Kondisi perangkat komunikasi yang terus menyala meskipun sedang tidak melakukan transmisi ataupun mengolah data. Hal ini mengakibatkan overhearing (mengolah data yang bukan untuknya).

d. Collision. Ketika sebuah node dengan node yang lain tidak saling mengetahui waktu mengirim data, maka akan terjadi tabrakan saat pengiriman data. Sehingga ketika terjadi tabrakan data maka node akan mengirimkan ulang data tersebut, hal ini tentu akan membutuhkan energi tambahan yang disebabkan proses dua kali pengiriman data.

Selain permasalahan yang sudah disebutkan, teknologi WSN memiliki kelebihan tersendiri, di antaranya[4]:

a. Dengan sistem wireless maka teknologi WSN dinilai lebih praktis dan fleksibel dibandingkan dengan wired sensor.

b. Sensor menjadi bersifat mobile, artinya node diatur agar memungkinkan dipindah titik pengukurannya untuk mendapatkan nilai deteksi lebih tepat tanpa harus mengubah perancangan denah tata letak dan area yang digunakan. 
c. Meningkatkan kinerja kontrol dan pemantauan hingga maksimal.

d. Mengurangi total biaya sistem secara signifikan.

e. Dapat mengumpulkan data dalam jumlah besar.

f. Konfigurasi software lebih mudah.

g. Memungkinkan Komunikasi digital 2 arah.

\subsection{Algoritman Leach}

Algoritma Leach adalah urutan atau langkah-langkah proses pengiriman data suatu WSN menggunakan sistem Leach [14]. Dalam sistem LEACH terbagi menjadi beberapa sesi, tergantung dari jumlah $\mathrm{CH}$ yang diinginkan dan masa observasi [15]. Leach mengatur untuk penetapan tiap node akan menjadi $\mathrm{CH}$ dalam sebuah sesi. Akibatnya, peran node sebagai $\mathrm{CH}$ dapat berubah-ubah pada setiap sesi [15]. Algoritma Leach dibagi menjadi 2 fase, yaitu fase setup dan fase steady state yang diperlihatkan pada Gambar 1 [15].

a. Fase Setup

Pada fase setup merupakan tahap saat sistem akan menentukan node yang ditugaskan sebagai $\mathrm{CH}$ dan proses pembentukan cluster (algoritma clustering).

b. Fase Steady State.

Pada fase steady state adalah tahap ketika sistem melakukan transmisi data antar node (mengirim dan menerima data hasil deteksi). Proses steady state memakan waktu yang lebih lama dibandingkan dengan proses setup, karena pengiriman data terjadi melalui transmisi radio secara intensif.

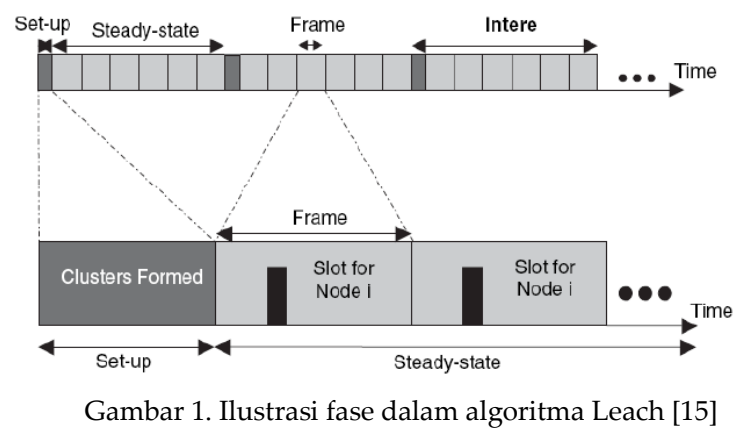

\subsection{Protokol Leach}

Leach merupakan protokol routing yang membentuk cluster dari kumpulan node sensor pada WSN berdasarkan kekuatan sinyal yang diterima [14]. Algoritma pada Leach dilakukan dengan pemilihan node sebagai $\mathrm{CH}$ terlebih dahulu. Kemudian dengan algoritma clustering, $\mathrm{CH}$ akan menentukan node sensor dengan jarak yang dekat dengan dirinya sebagai anggota cluster [16]. Protokol pada sistem ini menghemat energi karena hanya $\mathrm{CH}$ yang melakukan transmisi data ke Base Station (BS), untuk masing-masing node sensor cukup mengirim data ke $\mathrm{CH}$ yang berada pada cluster yang sama, hal ini diperlihatkan pada Gambar 2. Sehingga daya yang dikonsumsi lebih efisien dan masa hidup jaringan bisa bertahan lebih lama [15].

Penggunaan algoritma Leach, node-node akan dikelompokkan dalam sebuah cluster atau lebih pada sebuah jaringan. Setiap cluster memiliki sebuah cluster head yang memiliki dua tugas ganda, yakni memantau data objek serta mengontrol pengiriman data dari node sensor ke BS. Algoritma Leach memiliki fitur-fitur sebagai berikut [15]: 
a. Data fusion, yaitu penggabungan data sehingga mengurangi disipasi daya dan menambah lifetime jaringan.

b. Adaptive, yaitu mudah untuk menyesuaikan diri saat pembentukan formasi cluster

c. Local compression, yaitu mengkompresi data agar ukuran data yang dikirim ke BS lebih kecil.

d. Randomization rotation, yaitu melakukan perputaran kedudukan $\mathrm{CH}$ secara acak pada setiap sesi.

e. Self-Organizing, yaitu tiap node sensor memiliki sistem untuk menentukan sendiri menjadi $\mathrm{CH}$ atau node non-CH sesuai dengan bilangan acak yang didapatkan.

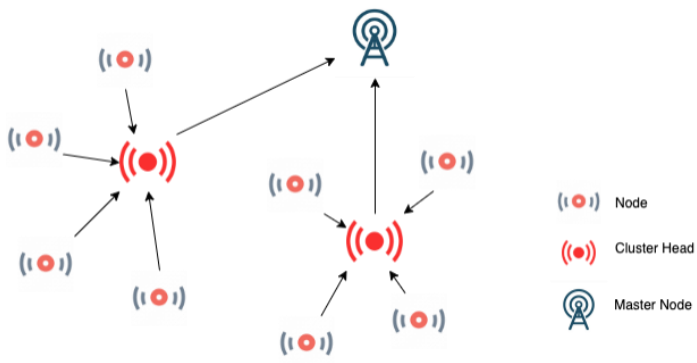

Gambar 2. Ilustrasi protokol Leach [15]

\section{Metode}

\subsection{Desain Node Sensor}

Desain pada node sensor dan cluster head diperlihatkan pada Gambar 3. Terdapat 5 buah komponen pendukung pada sebuah sensor node, yaitu Arduino Uno sebagai pemroses data, sensor arus dan tengangan yang berfungsi untuk memantau, real time clock digunakan sebagai penanda waktu serta modul LoRa sebagai modul komunikasi. Sedangkan pada algoritma 1 dijelaskan cara kerja pada node sensor.
Algoritma 1: Cara kerja node sensor
Input: real time control (RTC)
1: while $\mathrm{RTC}=5$ menit
2: nyalakan semua fitur
3: baca sensor
4: $\quad$ kirim data sensor ke cluster head
5: matikan semua fitur

Pada algoritma 1 dijelaskan urutan kerja dari node sensor. Dimulai dengan mikrokontroler membaca waktu yang diberikan oleh RTC untuk menentukan waktu node harus aktif. Desain yang digunakan adalah, pada setiap node akan aktif setiap 5 menit sehingga pada waktu tersebut semua fitur pada node akan diaktifkan. Setelah semua fitur berhasil aktif, maka mikrokontroler akan mulai memberikan perintah kepada sensor arus dan tegangan untuk mulai melakukan pembacaan data terhadap nilai tegangan dan arus baterai yang dikonsumsi oleh node dan beban lampu penerangan. Setelah mikrokontroler membaca hasil sensing maka data yang terbaca akan dikirimkan ke $\mathrm{CH}$ melalui LoRa. Setelah data selesai mengirim data maka node sensor akan kembali idle atau mematikan semua fitur. 


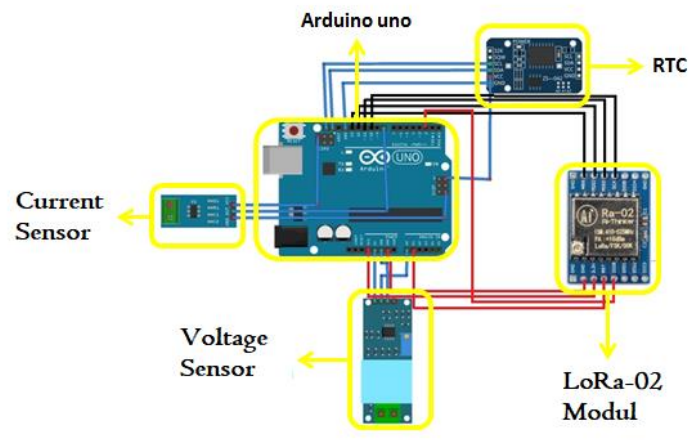

Gambar 3. Skematik rangkaian node sensor dan $\mathrm{CH}$

\subsection{Desain Cluster Head}

Cluster head bertanggung jawab untuk menerima dan meneruskan data dari node sensor ke server. Cara kerja pada cluster head dijelaskan pada algoritma 2.

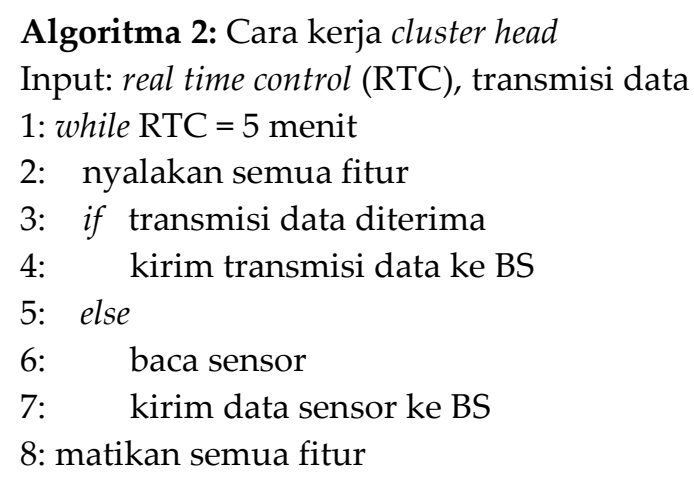

Pada algoritma 2, secara umum berfungsi hampir sama dengan node sensor, akan tetapi pada $\mathrm{CH}$ mempunyai dungsi lebih dibandingkan dengan node sensor yaitu sebagai jembatan, antara node sensor dengan server. Proses sensing pada $\mathrm{CH}$ ini sama dengan node sensor. Tetapi setelah mengirimkan data yang dibaca oleh dirinya sendiri, maka $\mathrm{CH}$ akan menerima data dari node sensor yang berada dalam cluster yang sama. Setelah menerima data, kemudian data akan diteruskan ke server.

\subsection{Desain Master Node}

Master node memiliki tugas untuk menerima data dari node (pada jaringan tanpa algoritma Leach) dan dari $\mathrm{CH}$ (pada jaringan dengan algoritma Leach). Pada penelitian ini master node menggunakan raspberry Pi sebagai untuk mengolah data dan raspberry pi juga dilengkapi dengan modul wireless LoRa sebagai transceiver. Selain sebagai pengolah data master node juga berfungsi sebagai server lokal dan akan mengirimkan data tersebut kepada server. Diagram skematik pada master node diperlihatkan pada Gambar 4. 


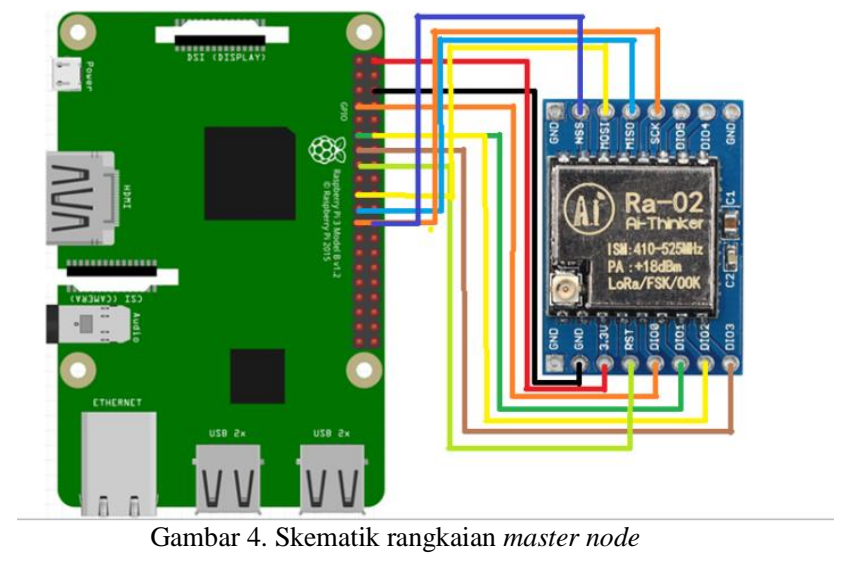

\subsection{Desain Perangkat}

Terdapat tiga buah bagian dalam perancangan sistem yang akan dibuat, yaitu sensor node, node $\mathrm{CH}$ dan master node. Blok diagram perancangan sistem yang akan dibuat diperlihatkan pada gambar 5 .
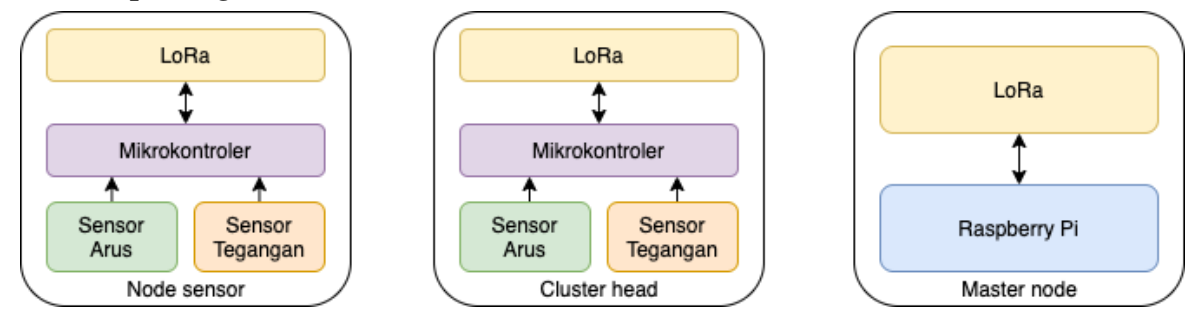

Gambar 5. Diagram blok perangkat

Pada diagram blok sistem yang diperlihatkan pada Gambar 5, node sensor berfungsi melakukan sensing pada lampu dan baterai, menggunakan sensor arus dan tegangan. Kemudian mikrokontroler pada node akan mengirimkan data ke $\mathrm{CH}$ menggunakan modul LoRa. CH menerima data yang dikirim oleh node sensor melalui LoRa. Selain mentransmisikan data dari node sensor, $\mathrm{CH}$ juga mengirimkan data hasil pembacaan sensor yang terdapat pada $\mathrm{CH}$ itu sendiri. Tujuan pengiriman dapa yang dilakukan oleh $\mathrm{CH}$ adalah kepada master node.

\subsection{Pemampatan Data pada Algoritma Leach}

Kompres data pada sistem algoritma Leach bertujuan untuk memampatkan data yang akan dikirim, ketika data sudah berhasil dimampatkan maka energi yang digunakan untuk proses transmisi data akan semakin kecil yang dijelaskan pada algoritma 3.

Gambar 6 menujukkan format pengiriman data pada algoritma Leach. Dalam satu paket pengiriman data terdapat dua bagian. Di antaranya, frame header paket yang berisikan alamat data akan dikirim dan frame data berisikan data hasil sensing dari setiap node. Frame header memuat alamat lengkap, yakni dari mana data berasal, $\mathrm{CH}$ tujuan, dan master node tujuan. Sedangkan frame data memuat tanggal dan jam proses sensing, nilai tegangan dan arus yang terukur. Namun pada tampilan website isi dari frame tidak ditampilkan, hanya menampilkan frame data sebagai nilai yang dipantau. 
Algoritma 3: Pemampatan data pada algoritma Leach Input: data

1: setiap data di node yang akan dikirimkan di pecah menjadi 2 frame (header dan value)

2: kirim data masing-masing frame ke $\mathrm{CH}$ secara serial

3: while $\mathrm{CH}$ menerima data frame dari node

4: Menyusun data frame sesuai dengan urutan

5: setiap data frame yang sudah disusun akan ditambahkan header $\mathrm{CH}$ sehingga menjadi slot $\mathrm{CH}$

6: kirim data frame ke BS

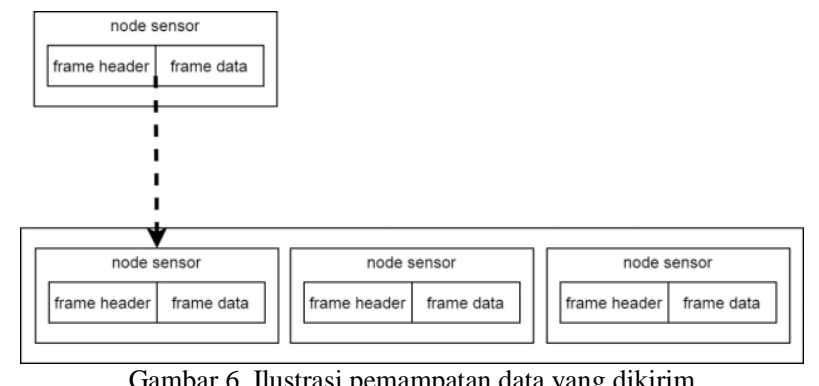

Gambar 6. Ilustrasi pemampatan data yang dikirim

\subsection{Slot dan Penjadwalan Dalam Pengiriman Data}

Penjadwalan saluran untuk pengiriman data pada algoritma Leach dimaksudkan untuk menghindari adanya tabrakan data serta implementasi sistem idle pada kontroler agar node tidak mengalami overhearing. Penjadwalan diterapkan pada node sensor dan $\mathrm{CH}$ dengan sistem pengiriman paket data dari node sensor akan diatur waktu pemgirimannya oleh CH menuju ke server [17].

Untuk penjadwalan saluran pengiriman data pada algoritma Leach ditentukan oleh banyaknya cluster dalam sistem yang dibangun. Untuk implementasi satu cluster berarti semua node dalam cluster hanya akan menggunakan satu saluran menuju $\mathrm{CH}$ dengan pergantian waktu tunggu (queue) berdasarkan random delay yang didapatkan masingmasing node dari program yang sudah diunggah pada mikrokontroler. Pada penelitian ini random delay ditentukan dari 0 s/d $5000 \mathrm{~ms}$.

Perbedaan jumlah cluster akan memengaruhi jumlah saluran yang akan digunakan untuk pengiriman data dari node sensor menuju ke server [18]. Untuk implementasi dua cluster maka ada dua saluran yang digunakan sesuai dengan $\mathrm{CH}$ dalam sistem. Setiap node yang tergabung dalam cluster terdekat dari $\mathrm{CH}$ akan mengirimkan datanya melalui saluran milik $\mathrm{CH}$ dalam satu cluster. Setiap cluster hanya dapat menggunakan saluran dari $\mathrm{CH}$ yang tergabung dalam satu cluster saja. Penjadwalan pada saluran $\mathrm{CH}$ untuk algoritma Leach satu cluster akan ditunjukan pada Gambar 7.

Pada Gambar 7, dapat dilihat bahwa untuk masing-masing node akan mengirimkan data pada $\mathrm{CH}$ sesuai dengan urutan dari random delay yang sudah didapatkan masingmasing node. Ketika node dalam kondisi menunggu antrian, maka node berada dalam kondisi aktif tetapi tidak melakukan transmisi data. Setelah node mengirim data ke $\mathrm{CH}$ kondisi node akan mati sesuai dengan program idle pada mikrokontroler. Untuk slot pada master node akan menerima semua data dari $\mathrm{CH}$ selama kondisi node menyala. Setelah semua proses transmisi data selesai maka semua node akan berada pada kondisi idle selama 
5 menit untuk setiap satu putaran transmisi data. Namun slot schedule ini hanya berlaku untuk satu cluster, sedangkan untuk dua cluster akan ditunjukkan pada Gambar 8.

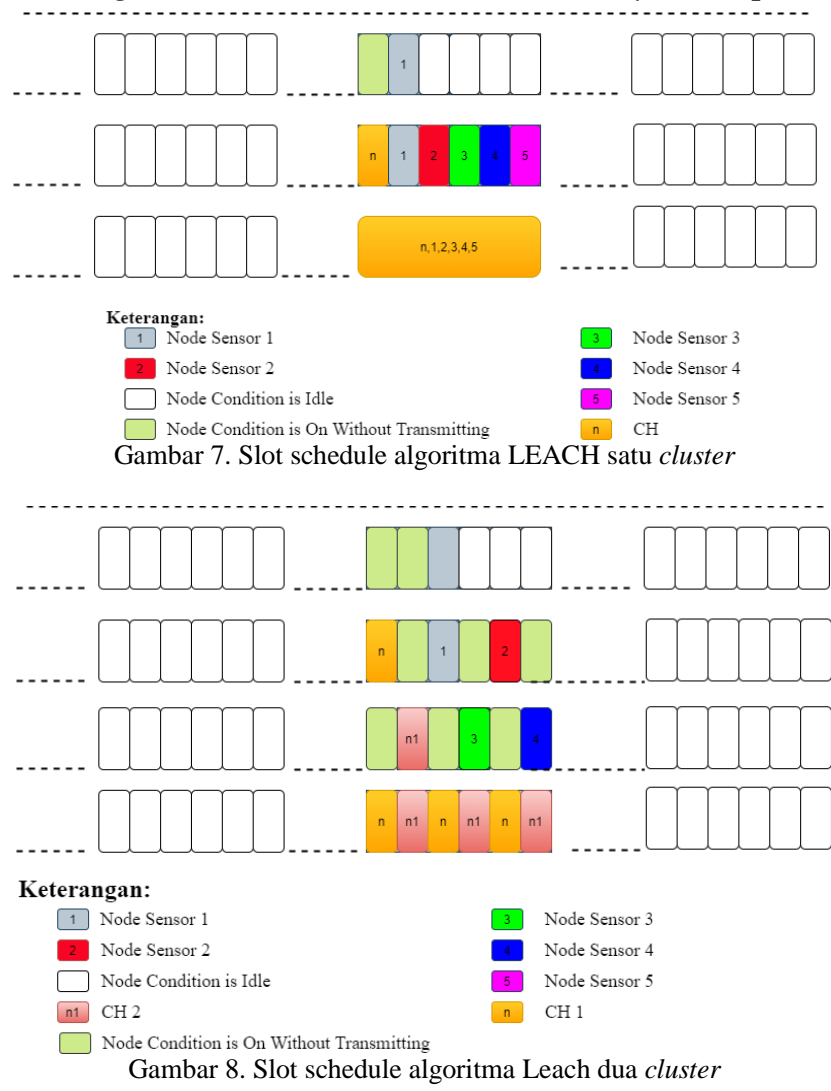

Untuk penjadwalan slot implementasi algoritma Leach dua cluster ditunjukkan pada Gambar 8. Pada node sensor akan mengirimkan data pada $\mathrm{CH}$ yang tergabung dalam satu cluster, tetapi antrian pada dua cluster bisa lebih panjang. Tampak pada Gambar 13 antrian untuk node sensor sebanyak dua slot. $\mathrm{CH}$ akan mengalami kondisi aktif tanpa melakukan transmisi data ketika melakukan antrian dengan cluster tetangga untuk proses pengiriman data ke server. Slot pada master node secara bergantian akan digunakan oleh $\mathrm{CH}$ dari masing-masing cluster secara bergantian. Setelah semua proses transmisi data selesai maka semua node akan berada pada kondisi idle selama 5 menit untuk setiap satu putaran transmisi data.

\section{Hasil dan Pembahasan}

Pada pengujian jaringan tanpa menggunakan algoritma Leach digunakan tiga (3) node sensor yang semuanya mengirim data hasil sensing pada master node secara bersamaan. Hasil pengujian disajikan dalam Gambar 9. Pada pengujian jaringan yang tidak menggunakan algoritma Leach dalam transmisinya data diambil pada jam yang sudah ditentukan. Dari Gambar 9 tampak semua node pada jam yang sama mengalami penurunan nilai tegangan dengan yang hampir sama. Penyebabnya adalah semua node langsung mengirimkan datanya ke master node tanpa melalui perantara. Tegangan baterai pada seluruh node berada pada nilai sekitar 7,5 volt di waktu yang bersamaan. Maka dengan begitu dapat dikatakan bahwa masa hidup jaringan tapa menggunakan algoritma Leach maksimal sebesar 60 jam. 


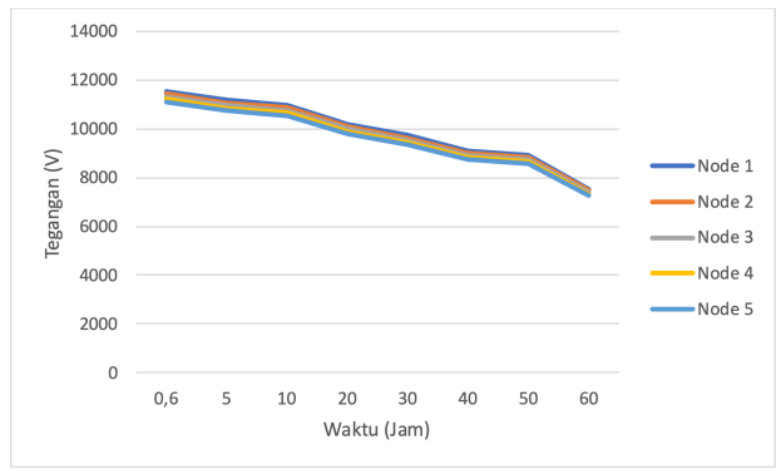

Gambar 9. Grafik masa hidup baterai pada jaringan non-Leach

Pengujian pengujian dengan menggunakan algoritma Leach. Digunakan dua buah node sebagai sensor node dan satu node sebagai $\mathrm{CH}$. proses pengiriman data dari masingmasing node menuju ke perangkat user menggunakan metode algoritma Leach. Data hasil pengujian disajikan pada Gambar 10.

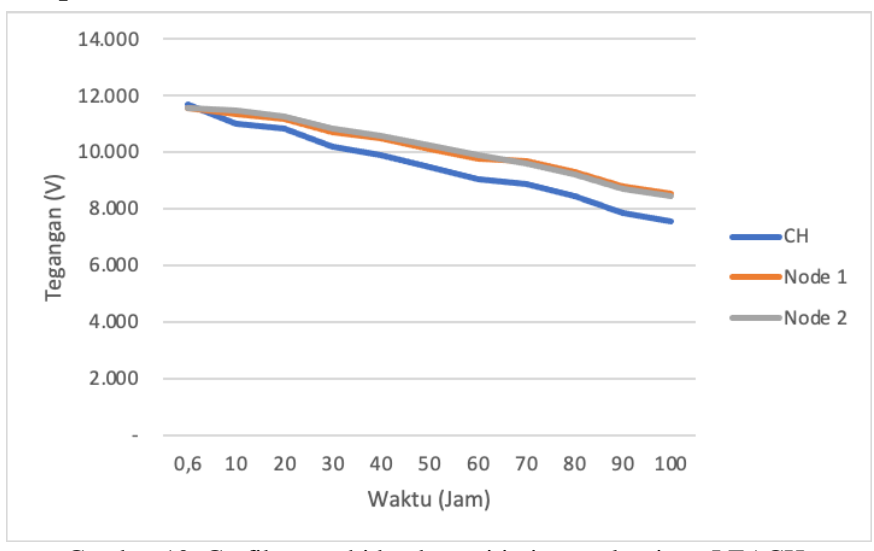

Gambar 10. Grafik masa hidup baterai jaringan algoritma LEACH.

Pada Gambar 10 tampak tegangan baterai $\mathrm{CH}$ lebih cepat turun nilainya dibanding dengan node sensor. Hal ini disebabkan tugas $\mathrm{CH}$ yang harus mengirimkan data 3 kali lebih banyak dibanding node sensor. Tegangan baterai $\mathrm{CH}$ sudah menyentuh tegangan minimal pada nilai 7,5 Volt. Maka perangkat pada $\mathrm{CH}$ sudah mati. Sistem tidak bisa melanjutkan proses pengiriman data ketika $\mathrm{CH}$ sudah tidak menyala. Namun untuk node sensor kondisinya masih menyala karena tegangan yang tersisa belum menyentuh tegangan minimal, dengan nilai tegangan rata-rata kelima node adalah 8 Volt. Node masih mampu melakukan aktifitas sensing namun datanya tidak dapat sampai ke server dikarenakan $\mathrm{CH}$ dalam kondisi tidak aktif. Sehingga dapat dikatakan bahwa masa hidup jaringan ketika menggunakan algoritma Leach maksimal sebesar 100 jam.

Jika dibandingkan, masa hidup pada implementasi algoritma Leach dalam sebuah cluster sebesar 100 jam dengan implementasi jaringan tanpa algoritma Leach dalam jumlah cluster yang sama juga sebesar 58 jam, maka nilai efisiensinya dapat dihitung menggunakan persamaan 1 .

$$
\begin{gathered}
\frac{L_{1}-L_{2}}{L_{1}} \times 100 \% \\
\frac{100-58}{100} \times 100 \%=42 \%
\end{gathered}
$$


di mana $\mathrm{L}_{1}$ adalah masa hidup dengan algoritma Leach sedangkan L2 adalah masa hidup jaringan tanpa jaringan Leach.

Berdasarkan hasil perhitungan menujukkan bahwa implementasi Algoritma Leach dalam satu cluster memiliki penggunaan daya lebih efisien $42 \%$ dibandingkan dengan tanpa menggunakan algoritma Leach.

\section{Kesimpulan}

Penggunaan algoritma Leach dalam satu cluster mempunyai efisiensi lebih baik sebesar $42 \%$ dibandingkan tanpa menggunakan metode Leach. Akan tetapi dalam penggunaan algoritma Leach waktu hidup atau lifetime $\mathrm{CH}$ menjadi lebih cepat habis, hal ini dikarenakan tugas $\mathrm{CH}$ yang lebih berat dibandingkan dengan tugas node sensor. Secara keseluruhan dengan nilai rata-rata penggunaan daya pada masing-masing perangkat dengan menggunakan algoritma Leach mempunyai kinerja lebih baik dibandingkan tanpa menggunakan algoritma Leach.

\section{Ucapan Terimakasih}

Penelitian ini didanai oleh program Penelitian Swadana Regular Kompetisi dari Politeknik Negeri Malang (023.18.2.677606/2021)

\section{Daftar Pustaka}

[1] T. U. Syamsuri, “Kontrol Lampu Jalan untuk Menghemat Energi,” Pros. SENTIA 2015, vol. 7, pp. 28-33, 2015.

[2] R. L. Nurbed, R. Munadi, and R. Mayasari, "Prototype Smart Street Lighting Di Wireless Sensor Network ( Prototype Smart Street Lighting in Wireless Sensor Network )," pp. 1-9.

[3] M. Taufik, A. E. Rakhmania, and Y. N. Afnani, "Prepaid water meter card based on internet of things," IOP Conf. Ser. Mater. Sci. Eng., vol. 732, no. 1, 2020.

[4] N. Afrian et al., "Rancang Bangun Pengendali Utama Pada Sistem Kontrol Dan Monitoring Lampu Penerangan jalan umum Tenaga Surya Menggunakan Wireless Sensor Network Dengan Human Machine Interface Terpusat," vol. 1, no. 1, pp. 110, 2017.

[5] H. Hudiono, M. Taufik, R. H. Y. Perdana, and W. R. Rohmah, "Design and implementation of centralized reading system on analog postpaid water meter," IOP Conf. Ser. Mater. Sci. Eng., vol. 732, no. 1, 2020.

[6] H. Darmono, R. H. Y. Perdana, and W. Puspitasari, "Observation of greenhouse condition based on wireless sensor networks," IOP Conf. Ser. Mater. Sci. Eng., vol. 732, no. 1, 2020.

[7] M. Syaifudin, F. Rofii, and A. Qustoniah, "Rancang Bangun Sistem Monitoring Tempat Sampah Rumah Tangga Dan Penerangan Jalan Berbasis Wireles Sensor Network (Wsn)," Transmisi, vol. 20, no. 4, p. 158, 2019.

[8] W. Cahyadi, M. A. Wahyudi, and C. S. Sarwono, "Analisis Perbandingan Konsumsi Energi dan Masa Hidup Jaringan pada Protokol LEACH, HEED, dan PEGASIS di Wireless Sensor Network," J. Rekayasa Elektr., vol. 14, no. 2, 2018.

[9] W. Puspitasari and H. Y. R. Perdana, "Real-time monitoring and automated control of greenhouse using wireless sensor network: Design and implementation," 2018 Int. 
Semin. Res. Inf. Technol. Intell. Syst. ISRITI 2018, pp. 362-366, 2018.

[10] H. L. D. A. N. Non-Leach, "Optimasi Network Lifetime Pada Jaringan Sensor Nirkabel Dengan Efisiensi Energi Menggunakan Teknik," vol. XV, no. 1, 2020.

[11] D. Wahyudi, M. U. H. Al Rasyid, and I. Syarif, "Implementasi Algoritma Clustering untuk Efisiensi Energi di Wireless Sensor Network," INOVTEK Polbeng - Seri Inform., vol. 4, no. 2, p. 168, 2019.

[12] K. Fallo, W. Wibisono, and Kun Nursyaful Priyo Pamungkas, "Pengembangan mekanisme grid based clustering untuk peningkatan kinerja LEACH pada lingkungan Wireless Sensor Network Development of a grid-based clustering mechanism to improve Leach performance in the Wireless Sensor Network environment," J. Ilm. Teknol. Sist. Inf., vol. 5, no. 34, pp. 152-161, 2019.

[13] Ifa Afidah Rosuliya, "Implementasi Routing Protokol Wireless Sensor Network Pada Mikrokontroler Implementation Routing Protocol Wireless Sensor Network Of Microcontroller Based," 2015.

[14] F. F. Kusumastuti, I. Wahidah, and R. Mayasari, "Analisis Perbandingan Konsumsi Daya dan Masa Hidup Jaringan pada Protokol Routing LEACH dan HEED di Wireless Sensor Network," Conf. Inf. Technol. Inf. Syst. Electr. Eng., pp. 57-64, 2016.

[15] M. A. Permana, "Analisa Algoritma LEACH Pada Jaringan Sensor Nirkabel," Proceeding Semin. Tugas Akhir Jur. Tek. Elektro FTI-ITS, pp. 1-6, 2012.

[16] I. Tonapa, J.R., Widiasari, “Analisis Ketahanan Energi Oleh Low Energy Adaptive Clustering Hierarchy ( LEACH ) Pada Cluster Head Wireless Sensor Network ( WSN ) Analisis Ketahanan Energi Oleh Low Energy Adaptive Clustering Hierarchy ( LEACH ) Pada Cluster Head Wireless Sensor Network," no. April, pp. $1-13,2016$.

[17] V. K. Ta, H. Oh, and M. Ieee, "A pipelined cooperative transmission protocol for fast and reliable image delivery in wireless sensor networks," pp. 1-14, 2020.

[18] R. H. Y. Perdana, H. Hudiono and A. F. N. Luqmani, "Water Leak Detection and Shut-Off System on Water Distribution Pipe Network Using Wireless Sensor Network," 2019 International Conference on Advanced Mechatronics, Intelligent Manufacture and Industrial Automation (ICAMIMIA), 2019, pp. 297-301. 